\title{
The discharge of individuals from hospital: Do we need to refocus our research?
}

\author{
Michelle Renee Guerin ${ }^{1}$, Karen Grimmer-Somers ${ }^{1}$, Saravana Kumar' ${ }^{1}$, Wendy Dolejs ${ }^{2}$ \\ 1. International Centre for Allied Health Evidence, Division of Health Sciences, University of South Australia, Australia. \\ 2. Operational Planning Unit, SA Health, Australia.
}

Correspondence: Michelle Guerin. Address: University of South Australia, Division of Health Sciences International Centre for Allied Health Evidence. City East Campus, GPO Box 2471, Adelaide SA 5001, Australia. Telephone: 08-8302-2075. E-mail: guemr002@mymail.unisa.edu.au

Received: December 6, 2011 Accepted: December 20, 2011 Published: August 1, 2012

DOI : 10.5430/jnep.v2n3p1

URL: http://dx.doi.org/10.5430/jnep.v2n3p1

Safe and timely discharge of individuals from hospital into the community continues to face a number of barriers. This is despite concerted research efforts to gain better understanding of processes of, and outcomes from, various discharge initiatives. During the doctoral research by the principal author, as with any research, more questions than answers were identified. One of the findings from this research, which incorporated both primary and secondary research methods, raised the question of the direction of future research into the discharge process of individuals from hospital. This question goes to the heart of discharge research, that is, is it time to consider researching discharge interventions which are multi-pronged and take a systems-wide approach? Such interventions need to actively engage policymakers, hospitals, community services and individuals, in order to develop possible solutions to the ongoing barriers which appear to have hindered improvements in the discharge process for over 30 years.

\section{Background}

There is a large volume of literature, published since the 1980s, which has generated regarding the processes of discharging individuals from hospital ${ }^{[1-10]}$. This considerable interest has been fuelled by the recognition of the crucial importance the discharge process can have on the utilisation of finite healthcare resources, hospital costs and individuals' outcomes ${ }^{[11-16]}$. Effective, timely and safe discharge of individuals from hospital is necessary to ensure appropriate utilisation of limited hospital resources by those who are acutely ill; assist in containing rising hospital costs; reduce unplanned readmissions following discharge; and optimise individuals' outcomes in terms of health, function and levels of satisfaction ${ }^{[11-16]}$. While there is no dispute about the importance of effective, timely and safe discharge, how best to achieve this in practice remains problematic ${ }^{[7,15,17]}$. In order to explore why this is still the case, this paper examines two large bodies of research conducted into the discharge process over the past 30 years. Understanding this past evidence provides not only a platform for discussion into why current research has not sufficiently informed practice, but also identifies opportunities for future research directions.

The first large body of discharge research was undertaken predominately in the 1990s and early 2000s. It was concerned with investigating and further understanding the discharge process of individuals from hospital. This body of work identified that the discharge process is highly complex, fragile and prone to breakdown ${ }^{[1,4,18]}$. Successful discharge is contingent on numerous factors, and a breakdown in any of these can adversely influence effective, timely and safe discharge. Factors which have been consistently identified in the literature, as negatively influencing the discharge 
process, include: poor communication; inadequate and delayed assessments; poor organization and limited community resources ${ }^{[1,4,18-21]}$. By exploring each of these factors in more detail below, we aim to provide a context for discussion of future directions for research into discharge planning.

\section{Poor communication}

Fundamental to the discharge process is communication between key stakeholders, in hospitals, and across the hospital-community interface ${ }^{[1,4,18,19,22]}$. Bull and Roberts ${ }^{[4]}$ identified three 'circles' of communication necessary for 'proper' discharge. The 'first circle' involved communication between hospital staff in relation to the discharge process. The 'second circle' included communication between hospital staff and the individual being discharged and their family members/carers. The 'third circle' comprised communication across the hospital-community interface (between hospital and community staff). Poor communication between key stakeholders involved in the discharge process is a fundamental barrier to effective, timely and safe discharge. Jewell ${ }^{[18]}$ proposed that poor communication may be the origin of the majority of problems experienced in the discharge process, delaying discharge from hospital and compromising patient safety.

There are well-reported limitations to communication (verbal and written) within the hospital environment ${ }^{[4,19,21,23]}$. Communication between hospital staff, regarding individual's discharge plans, frequently breakdown due to poor documentation of discharge plans in case notes, staffing rotations, and the busy nature of the hospital environment $^{[1,2,4,18,19,22,23]}$. Likewise, communication between hospital staff and individuals and their family/carers regarding discharge, is frequently reported to be insufficient ${ }^{[18,21]}$. Problems attributed to communication issues include lack of engagement of individuals and family/carers in the discharge process, the overt reliance on verbal information exchange and the provision of inadequate written and verbal information to inform ongoing care following discharge (e.g. medication management, diet, symptom management, or ongoing community support) ${ }^{[2,18,24,25]}$.

Inadequate communication of accurate and relevant information between hospital and community staff is common. Problems include illegible written discharge summaries, discharge summaries containing inaccurate or insufficient information to inform the provision of care, delays in receiving discharge summaries, and difficulties in being able to contact staff members across the hospital-community interface ${ }^{[1,4,18,19,21,26]}$. Middleton et al. ${ }^{[27]}$ in their study of Australian general practitioners identified that only $44.1 \%$ of general practitioners had received a discharge summary within two weeks of an individual being discharged from hospital. Of these discharge summaries, only $67.3 \%$ were considered by the general practitioners to be at least 'useful' in informing care.

The effective, timely and safe discharge of individuals from hospital is related to the establishment of information exchange structures and the quality of communication between staff and between staff and individuals. Only then can quality discharge be achieved.

\section{I nadequate or delayed assessment of individuals needs}

Prompt and thorough assessment of patients' discharge needs is required to facilitate effective, timely and safe discharge. Best practice discharge guidelines suggest that with respect to unplanned admissions to hospital, discharge assessments should commence as soon as practical after admission, with many guidelines recommending a timeframe of 24 to 48 hours ${ }^{[28-31]}$. Discharge assessments need to consider the medical history as well as broader issues which may influence patients' ability to return home. Issues such as pre-admission level of functioning, home environment, social support, and individual's preferences for leaving hospital, have been identified in the literature as important parts of a holistic discharge assessment ${ }^{[18]}$. Undertaking prompt and thorough discharge assessments, in collaboration with family members and carers, provides the greatest opportunity for any issues identified to be addressed throughout the stay in hospital. This is particularly important in today's healthcare environment where the average length of hospital stay is relatively short ${ }^{[32,33]}$. 
In Australia the average length of hospital stay (including same-day separations) in 2009-2010 was 3.6 days in public hospitals and 2.4 days in private hospitals ${ }^{[33]}$.

In practice however, assessments to assist in planning for an individual's discharge may be delayed and inadequate. Discharge assessments frequently occur late in an individual's stay in hospital, namely on the day of discharge ${ }^{[22,23]}$. Delays in undertaking discharge assessments are attributed to confusion around roles regarding who is responsible for undertaking and coordinating discharge assessments, and the busy hospital environment where nurses prioritise providing medical care over arranging discharge ${ }^{[18,23]}$. Where discharge assessments occur late in an individual's hospital stay, there is greater potential for incomplete discharge plans and/or delayed discharge. This is due to shorter time available to address specific discharge issues which were identified through the assessment process, or subsequent hospital stay; limited time to engage appropriate community services to provide necessary ongoing care in the community; and fewer opportunities to involve individual's family and carers in facilitating the patient's discharge from hospital to community.

The collection of inadequate information to inform appropriate discharge planning is also a common problem. Questions around individual's home environment and social support are frequently omitted as part of the discharge assessment ${ }^{[21,22]}$. Potential reasons proposed for this are: a lack of understanding by hospital staff of the influence these factors can have on discharge; and a lack of systems and processes underpinning discharge assessments ${ }^{[1]}$. Collection of inadequate discharge information can result in individuals being discharged home into unsafe environments, with inadequate support, and/or community services receiving inappropriate referrals resulting in reorganisation of services once the individual is home ${ }^{[1,18]}$.

The development of processes and structures within hospitals, and between hospital and community services are necessary to support the prompt and comprehensive assessment of individuals to inform effective, timely and safe discharge from hospital.

\section{Poor organisation}

Arranging an individual's discharge from hospital can involve a range of organisational activities, which are usually instigated in hospital and continue into the community ${ }^{[4,18]}$. This process can be complex, iterative and time-consuming, relying heavily on collaboration and effective communication within hospital and across the hospital-community interface ${ }^{[22-24]}$. Within hospital, the poor organization of activities, such as, referrals to multidisciplinary teams to undertake necessary assessments (e.g. occupational therapists, social workers); the ordering and reconciling of individuals discharge medications; the education of individuals and family or carers regarding ongoing care (e.g. diet, wound care) and medication management; and arranging transport from hospital, are frequent causes of delayed discharge ${ }^{[18,20,34]}$. Victor ${ }^{[20]}$ identified that delays in referrals to multidisciplinary staff was one of the main organisational factors associated with delayed discharges from hospital.

The coordination of activities between hospital and community staff is necessary to assist in continuity of care throughout the discharge process, and ensure appropriate supports are in place by the time of discharge ${ }^{[1,4,34]}$. This is particularly important for individuals who live alone and have limited or no family support, as these individuals are often reliant on community services to meet their ongoing care needs once discharged from hospital ${ }^{[20,35]}$. Poor organisation between hospital and community staff can be attributed to rushed discharges from hospital; limited hospital staff time to engage community services; lack of knowledge by hospital staff of who to contact in the community; and inadequate communication across the interface ${ }^{[1,34]}$. Poor coordination of services across the interface may result in delays in discharge requiring individuals to remain in hospital until the requisite community services can be instigated. Alternatively, individuals may be discharged with insufficient service provision to meet their needs, potentially comprising their safety. Bull \& Roberts ${ }^{[4]}$ identified in their study that district nurses required about three days notice of an individual's planned discharge from hospital in order to arrange the necessary services and staffing. 
Appropriate and timely organisation of discharge activities involving hospital staff, individuals and their family/carers, and community services may facilitate the effective, timely and safe discharge of individuals from hospital. Systems and processes need to underpin the organisation of these discharge activities, so to guide clinical practice.

\section{Limited community resources}

Hospital stays, on average, are short which can contribute to many individuals having ongoing care needs following discharge from hospital (e.g. medication management, assistance with activities of daily living, wound care) which require care and support from community services ${ }^{[36]}$. As mentioned previously, this is particularly the case for those whom live alone and have limited or no family support ${ }^{[20]}$. Consequently, the availability of community services can influence an individual's ability to leave hospital. In situations where there are insufficient community resources to meet an individual's needs upon discharge, they may remain in hospital, resulting in delayed discharge and increased risk of developing hospital-related complications ${ }^{[14,20]}$.

Insufficient community resources are associated with long waiting lists for services, staffing availability, and deficits in certain types of community services (e.g. lack of mental health services, rehabilitation services) ${ }^{[1,4,20]}$. Wong et al. ${ }^{[37]}$ in a recent study identified that weekend hospital discharge rates were significantly lower than during the week. One explanation they proposed for this was that it was not feasible to discharge individuals requiring community services over the weekend, as services were often not available. Hence, individuals remained in hospital over the weekend and were discharged early in the week once community services could provide the requisite care.

Community resource availability and its impact on discharge from hospital are likely to differ between regions, due to local variability of resources, funding and demographics. In attempting to improve effective, timely and safe discharge from hospital, local variability in community resources needs to be considered, and collaborative efforts between hospitals and community services should be undertaken to identify the best ways to address these issues.

\section{Reasons for lack of progress}

Discharging individuals from hospital in an effective, timely and safe manner is greatly influenced by the four key organisational factors discussed above; poor communication; inadequate and delayed assessments; poor organisation; and limited community resources ${ }^{[1,4,18-21]}$. These factors are wide ranging, involving local hospital and community service structures, individuals and their families/carers, and broader system wide policies, procedures and funding arrangements. Above all, it is likely that effective, timely and safe discharge is reliant on a complex interplay between these factors. For example, regardless of how prompt and thorough an individual's discharge assessment is, if there are not the available community resources to meet their discharge needs, they are unlikely to be able to be discharged in a timely manner. Similarly, it does not matter how well discharge information is communicated within hospital and across the hospital-community interface, if the information being communicated is inadequate, or incorrect, due to poor assessment processes.

Building on this understanding, gained from the first body of evidence, was a second body of research focused on identifying potential ways to improve the discharge process and the resultant outcomes (mainly healthcare and individual). This body of research, comprising mostly of experimental studies and systematic reviews, was predominately published in the late 1990s and throughout 2000. However, this large of body of work, on the whole, has failed to identify practical system-wide solutions to the longstanding barriers influencing effective, timely and safe discharge. This is principally the case for three main reasons.

Firstly, many studies focus more on reporting on the outcomes of the intervention, such as hospital readmission, mortality and length of hospital stay, rather than providing a detailed account of the intervention and the processes involved. For 
example, Kwok et al. 's ${ }^{[38]}$ study of community nurse-supported discharge of older individuals with chronic heart failure, focused predominately on reporting on outcomes of unplanned readmissions, health care and personal costs, and functional outcomes (e.g. walking). The reported overview of the intervention focused on detailing the times of interaction between the community nurse and the individual, and provided a brief summary of what occurred at each visit. However, information pertaining to broader systems and procedures, such as communication and information exchange between staff and the individual, assessment processes and timing, and engagement of the community nurse, were not provided.

Similarly, Rytter et al. ${ }^{[39]}$ researched the effect of follow-up visits by general practitioners and community nurses on readmission rates, general practitioners knowledge of medication treatments and implementation of discharge interventions, healthcare costs and individual functional outcomes (e.g. functional ability, self-rated health). Again, a brief summary of the intervention outlining the schedule of visits between the health professionals (general practitioner and community nurse) and the individual and what occurred at each visit was reported. Details not described within the study included: how broader processes operated, such as engagement of general practitioners and community nurses by the hospital; information and communication exchange; and discharge assessment processes. A lack of detail regarding the intervention and surrounding processes limits the ability to critique how possible interventions addressed, or did not address, the common discharge barriers. In order to inform clinical practice and to develop a body of literature regarding possible solutions to the longstanding barriers in the discharge process, further research needs to include a more detailed account of the intervention studied. This account needs to include details regarding communication processes, assessment tools and timing, organisation of discharge activities in hospital and across the hospital-community interface, and the availability and responsiveness of community services.

Secondly, many studies tend to identify a specific service intervention that facilitates an individual's discharge from hospital (e.g. hospital nurse providing education and follow-up after discharge for a specific cohort of individuals) and dependent on the outcomes, conclude that the service may, or may not, be of value in facilitating effective, timely and safe discharge. This is often without detailed consideration of the suggested solution. For instance, if we consider the example of hospital nurses providing education and follow-up visits, should this same intervention also be trialed with community nurses or other health practitioners? Alternatively, it could be trialed with a combination of hospital nurses providing education in hospital, and follow-up visits by community nurses. Greater analysis of the intervention would enable further insight into the intervention and which systems and processes are important in influencing outcomes. For instance, was it the education and follow-up visits that contributed to the outcomes, or was it better communication with the individual being discharged from hospital, or were there less opportunities for communication breakdowns across the hospital-community interface, or was it responsive follow-up services following discharge from hospital? Future discharge research needs to include the critical review of suggested interventions. This would provide a greater level of understanding about how the intervention influences the discharge process, and which systems or processes are impacted upon. This level of understanding would enhance the translation of discharge research into clinical practice, and would enable one to determine whether the real barriers to effective, timely and safe discharge are being addressed, or simply the symptoms.

Thirdly, the majority of experimental studies and systematic reviews provide no local healthcare context surrounding the discharge intervention(s) being researched. Many studies provide limited explanation regarding why a particular intervention was designed and researched at a specific hospital(s), and the reasoning behind how the intervention aimed to improve the discharge process, compared to 'usual' practices. For example, did the intervention aim to address systems issues such as communication, or was the aim to change staffing factors, such as, team arrangements or clinical knowledge? Limited explanation as to why a specific intervention was researched in a local area and how it aimed to modify the discharge process, compared with 'usual' care, limits the ability to critically evaluate the outcomes of the research. Given the complex and inter-related nature of discharge barriers, non-significant healthcare and individual outcomes may not necessarily reflect an ineffective intervention. Rather, other discharge barriers may have influenced the outcomes, contributing to non-significant findings. For example, in an environment where the main barrier is inadequate 
and delayed discharge assessments and where community services have capacity to be responsive in providing follow-up care in the community, a hospital-based multi-disciplinary assessment team may be an effective intervention to improve the discharge process in terms of hospital length of stay, reduced hospital costs and individual outcomes. Yet, the same intervention delivered in a system where community services did not have adequate capacity to be responsive and individuals had to remain in hospital awaiting community input, is unlikely to demonstrate the same significant findings.

In order to assist in translating findings into practice and to identify solutions to the inherent organisational barriers in the discharge process, further discharge research needs to be positioned within the local healthcare context. This local context needs to include information pertaining to the reasoning behind the specific intervention and the factors which the intervention aims to address. Outcomes collected and reported upon also need to ensure they reflect this level of detail.

\section{Conclusion}

It is clear that despite a large body of evidence, we still do not have strategies to address the long standing, system wide, barriers hindering effective, timely and safe discharge. If we are serious about addressing these issues we need to refocus our research to address the inherent barriers associated with the discharge process, from all stakeholders' perspectives. This research will require the unification of hospitals, community service providers, individuals and their families/carers, and policymakers to develop research and implement system wide interventions which aim to improve the discharge process and the outcomes for all stakeholders. This new approach will also call for contemporary research methods, which utilise a combination of qualitative and quantitative methods in order to respond to these complex systems issues.

\section{References}

[1] Armitage S, Kavanagh K. Continuity of care: discharge planning and community nurses. - Paper presented at the Research for Practice International Nursing Conference (1995: Newcastle, NSW). Contemporary Nurse [Internet]. 1995; 4(4): 148-155. Available from: http://www.contemporarynurse.com/ PMid:8696041 http://dx.doi.org/10.5172/conu.4.4.148

[2] Armitage SK, Kavanagh KM. Consumer-orientated outcomes in discharge planning: a pilot study. J Clin Nurs [Internet]. 1998; 7: 67-74. Available from: http://onlinelibrary.wiley.com/journal/10.1111/(ISSN)1365-2702 PMid:9510710 http://dx.doi.org/10.1046/j.1365-2702.1998.00136.x

[3] Bauer M, Fitzgerald L, Haesler E, Manfrin M. Hospital discharge planning for frail older people and their family. Are we delivering best practice? A review of the evidence. J Clin Nurs [Internet]. 2009; 18: 2539-2546. Available from: http://onlinelibrary.wiley.com/journal/10.1111/(ISSN)1365-2702 PMid:19374695 http://dx.doi.org/10.1111/j.1365-2702.2008.02685.x

[4] Bull MJ, Roberts J. Components of a proper hospital discharge for elders. J Adv Nurs [Internet]. 2001; 35:571-581. Available from: http://onlinelibrary.wiley.com/journal/10.1111/(ISSN)1365-2648 PMid:11529957 http://dx.doi.org/10.1046/j.1365-2648.2001.01873.x

[5] Hyde CJ, Robert IE, Sinclair AJ. Effects of supporting discharge from hospital to home in older people. Age Ageing [Internet]. 2000 May; 29(3): 271-279. Available from: http://ageing.oxfordjournals.org/ PMid:10855913 http://dx.doi.org/10.1093/ageing/29.3.271

[6] Christopher P, Scott W, David K, Ramesh S, Sasha S, Haya R. Comprehensive Discharge Planning With Postdischarge Support for Older Patients With Congestive Heart Failure: A Meta-analysis. JAMA [Internet]. 2004; 291(11): 15/4/2007-1358-1367. Available from: http://jama.ama-assn.org/

[7] Parker SG. Do current discharge arrangements from inpatient hospital care for the elderly reduce readmission rates, the length of inpatient stay or mortality, or improve health status? Health Evidence Network Report [Internet]. 2005. Available from: http://www.euro.who.int/_data/assets/pdf_file/0006/74670/E87542.pdf

[8] Parker G, Peet SM, McPherson A, Cannaby AM, Abrams K, Baker R, et al. A systematic review of discharge arrangements for older people. Health Technology Assessment. 2002; 6(4): 1-183.

[9] Shepperd S, McClaran J, Phillips C, Lannin N, Clemson L, McCluskey A, et al. Discharge planning from hospital to home. Cochrane Database of Systematic Reviews. 2010. http://dx.doi.org/10.1002/14651858.CD000313.pub3 
[10] Skeet M. Home from Hospital: The Results of a Survey Conducted Among Recently Discharged Hospital Patients. London: Dan Mason Nursing Research Committee: National Florence Nightengale Memorial Committee. 1974.

[11] Proudlove NC, Gordon K, Boaden R. Can good bed management solve overcrowding in accident and emergency departments? Emergency Medicine Journal [Internet]. 2003; 20: 149-155. Available from: http://emj.bmj.com/ PMid:12642528 http://dx.doi.org/10.1136/emj.20.2.149

[12] Yam CHK, Wong ELY, Chan FWK, Leung MCM, Wong FYY, Cheung AWL, et al. Avoidable readmission in Hong Kongsystem, clinician, patient or social factors? BMC Health Services Research [Internet]. 2010; 10:311. Available from: http://www.biomedcentral.com/content/pdf/1472-6963-10-311.pdf. PMid:21080970 http://dx.doi.org/10.1186/1472-6963-10-311

[13] Hoot NR, Aronsky DA. Systematic review of emergency department crowding: causes, effects and solutions. Annals of Emergency Medicine [Internt]. 2008; 52(2): 126-136. Available from: http://www.annemergmed.com/ PMid:18433933 http://dx.doi.org/10.1016/j.annemergmed.2008.03.014

[14] Lim SC, Doshi V, Castasus B, Lim JKH. Factors causing delay in discharge of elderly patients in an acute care hospital. Annals of Academy of Medicine [Internt]. 2006; 35(1): 27-32. Available from: http://www.annals.edu.sg/

[15] Scott IA. Preventing the rebound: improving care transition in hospital discharge processes. Australian Health Review [Internet]. 2010; 34: 445-451. Available from: http://www.publish.csiro.au/?act=view_file\&file_id=AH09777.pdf PMid:21108906 http://dx.doi.org/10.1071/AH09777

[16] Mor V, Besdine RW. Policy Options to Improve Discharge Planning and Reduce Rehospitalization. JAMA [Internet]. 2011; 305(3): 302-303. Available from: http://jama.ama-assn.org/ PMid:21245187 http://dx.doi.org/10.1001/jama.2010.2006

[17] Day P, Rasmussen P. What is the evidence for the effectiveness of specialist geriatric services in acute, post-acute and sub-acute settings? NZHTA Report [Internet]. 2004; 7(3). Available from: http://www.otago.ac.nz/christchurch/otago014036.pdf

[18] Jewell SE. Discovery of the discharge process: a study of patient discharge from a care unit for elderly people. J Adv Nurs [Internet]. 1993; 18: 1288-1296. Available from: http://onlinelibrary.wiley.com/journal/10.1111/(ISSN)1365-2648 PMid:8376668 http://dx.doi.org/10.1046/j.1365-2648.1993.18081288.x

[19] Kripalani S, LeFevre F, Phillips C, Williams M, Basaviah P, Baker D. Deficits in communication and information transfer between hopsital-based and primary care physicians - Implications for patient safety and continuity of care. JAMA [Internet]. 2007; 297(8): 831-841. Available from: http://jama.ama-assn.org/ PMid:17327525 http://dx.doi.org/10.1001/jama.297.8.831

[20] Victor CR, Healy J, Thomas A, Seargeant J. Older patients and delayed discharge from hospital. Health \& Social Care in the Community [Internet]. 2000; 8: 443-452. Available from: http://www.wiley.com/bw/journal.asp?ref=0966-0410 PMid:11560715 http://dx.doi.org/10.1046/j.1365-2524.2000.00270.x

[21] Mesteig M, Helbostad JL, Sletold O, Rosstad T, Saltvedt I. Unwanted incidents during transition of geriatric patients from hospital to home: a prospective observational study. BMC Health Services Research [Internet]. 2010; 10(1): 1472-6963/10/1. Available from: http://www.biomedcentral.com/content/pdf/1472-6963-10-1.pdf

[22] Watts R, Gardner H. Nurses’ perceptions of discharge planning. Nurs Health Sci [Internet]. 2005 September; 7: 175-183. Available from: http://onlinelibrary.wiley.com/journal/10.1111/(ISSN)1442-2018 PMid:16083480

http://dx.doi.org/10.1111/j.1442-2018.2005.00229.x

[23] Atwal A, Caldwell K. Do multidisciplinary integrated care pathways improve interprofessional collaboration? Scand J Caring Sci [Internet]. 2002; 16: 360-367. Available from: http://www.wiley.com/bw/journal.asp?ref=0283-9318 PMid:12445105 http://dx.doi.org/10.1046/j.1471-6712.2002.00101.x

[24] Driscoll A. Managing post-discharge care at home: an analysis of patients' and their carers' perceptions of information received during their stay in hospital. Journal of Advanced Nursing [Internet]. 2000; 21(5): 1165-1173. Available from:

http://onlinelibrary.wiley.com/journal/10.1111/(ISSN)1365-2648 PMid:10840250

http://dx.doi.org/10.1046/j.1365-2648.2000.01372.x

[25] Suhonen R, Nenonen H, Laukka A, Valimaki M. Patients' informational needs and information received do not correspond in hospital. J Clin Nurs [Internet]. 2005; 14: 1167-1176. Available from:

http://onlinelibrary.wiley.com/journal/10.1111/(ISSN)1365-2702 PMid:16238762

http://dx.doi.org/10.1111/j.1365-2702.2005.01233.x

[26] Satzinger W, Courté-Wienecke S, Wenng S, Herkert B. Bridging the information gap between hospitals and home care services: experience with a patient admission and discharge form. J Nurs Manag [Internet]. 2005; 13(3):257-264. Available from: http://onlinelibrary.wiley.com/journal/10.1111/(ISSN)1365-2834 PMid:15819839 http://dx.doi.org/10.1111/j.1365-2834.2005.00542.x

[27] Middleton S, Appleberg M, Girgis S, Ward JE. Effective discharge policy: are we getting there? Australian Health Review [Internet]. 2004 Dec; 28(3): 255-259. Available from: http://www.publish.csiro.au/?act=view_file\&file_id=AH09777.pdf PMid:15595906 http://dx.doi.org/10.1071/AH040255 
[28] Queensland Health. Guidelines for pre-admission processes, discharge planning and transitional care [Internet]. 1998. Available from: http://www.health.qld.gov.au/surgical_access/doc/preadmin_etc.pdf

[29] National Stroke Foundation. Clinical Guidelines for Stroke Management. Melbourne Australia [Internet]. 2010. Available from: http://www.nhmrc.gov.au/_files_nhmrc/publications/attachments/cp126.pdf

[30] Department of Human Services. Improving patient transition from hospital to the community: a good practice guide [Internet]. 2003. Available from: http://www.health.vic.gov.au/archive/archive2008/discharge/patrans.htm

[31] ACT Health Policy Division. ACT Health Discharge Planning Policy [Internet]. 2006. Available from: http://www.health.act.gov.au/c/health?a=dlpubpoldoc\&document=883

[32] US Department of Health and Human Services. Agency for Healthcare Research and Quality: Advancing Excellent in Health Care [Internet]. Available from: http://www.ahrq.gov/

[33] Australian Institute of Health and Welfare. Australian hospital statistics 2009-10. Health services series [Internet]. 2011. Available from: http://www.aihw.gov.au/publication-detail/?id=10737418863

[34] Mukotekwa C, Carson E. Improving the discharge planning process: a systems study. Journal of Research in Nursing [Internet]. 2007; 12(6): 667-686. Available from: http://jrn.sagepub.com/ http://dx.doi.org/10.1177/1744987107078897

[35] Grimmer K, Moss J, Falco J. Experiences of elderly patients regarding independent community living after discharge from hospital: a longitudinal study. Int J Qual Health Care [Internet]. 2004 Dec; 16(6): 465-472. Available from: http://intqhc.oxfordjournals.org/ PMid:15557356 http://dx.doi.org/10.1093/intqhc/mzh071

[36] Quian X, Russell LB, Valiyeva E, Miller JE. 'Quicker and Sicker' under medicare's prospective payment system for hospitals: New evidence on an old issue from a national longitudinal survey. Bulletin of Economic Research [Internet]. 2011; 63(1): 1-27.

Available from: http://www.wiley.com/bw/journal.asp?ref=0307-3378 PMid:21141646 http://dx.doi.org/10.1111/j.1467-8586.2010.00369.x

[37] Wong FK, Mok MP, Chan T, Tsang MW. Nurse follow-up of patients with diabetes: randomized controlled trial. J Adv Nurs [Internet]. 2005 May; 50(4): 391-402. Available from: http://onlinelibrary.wiley.com/journal/10.1111/(ISSN)1365-2648 PMid:15842446 http://dx.doi.org/10.1111/j.1365-2648.2005.03404.x

[38] Kwok T, Lum CM, Chan HS, Ma HM, Lee D, Woo J. A Randomized Controlled Trial of an Intensive Community Nurse-Supported Discharge Program in Preventing Hospital Readmissions of Older Patients with Chronic Lung Disease. J Am Geriatr Soc [Internet]. 2004; 52: 1240-1246. Available from: http://www.wiley.com/bw/journal.asp?ref=0002-8614\&site=1 PMid:15271109 http://dx.doi.org/10.1111/j.1532-5415.2004.52351.x

[39] Rytter L, Jakobsen HN, Ronholt F, Hammer AV, Andreasen AH, Nissen A, et al. Comprehensive discharge follow-up in patients' homes by GPs and district nurses of elderly patients: A randomised controlled trial. Scandinavian Journal of Primary Health Care [Internet]. 2010; 28: 146-153. Available from: http://www.sjphc.org/ PMid:20429738 http://dx.doi.org/10.3109/02813431003764466 